\title{
ACCESIBILITY TO AND CONSUMPTION OF INDIGENOUS VEGETABLES AND FRUITS BY RURAL HOUSEHOLDS IN MATUNGU DIVISION, WESTERN KENYA
}

Ekesa $\mathrm{BN}^{1}$, Walingo $\mathrm{MK}^{2}$ and MO Abukutsa-Onyango ${ }^{3}$

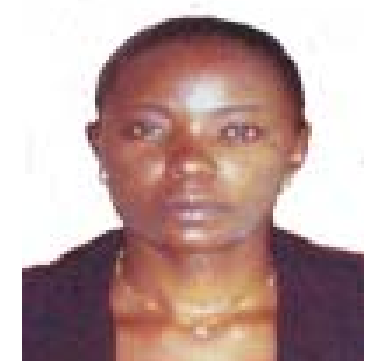

Ekesa Beatrice

Corresponding author email: nakhauka@yahoo.com or b.ekesa@cgiar.org

${ }^{1}$ Bioversity International, Katalima Road, Plot 106, P.O. Box 24384, Kampala, Uganda.

${ }^{2}$ Maseno University, School of Public Health and Community Development, P.O. Box 333, Maseno, Kenya.

${ }^{3}$ Jomo Kenyatta University of Agriculture and Technology, Faculty of Agriculture, P.O. Box 62000-00200, Nairobi, Kenya. 


\begin{abstract}
Unacceptably high rates of micronutrient deficiencies persist mostly among resourcepoor communities who rely on subsistence farming. In these communities, consumption of vegetables and fruits is the most sustainable way of reducing micronutrient deficiencies. Apart from enhancing dietary diversity, indigenous vegetables and fruits are often easier to grow, resistant to pests, acceptable to local tests, rich and cheap sources of micronutrients. Despite this, they are mostly associated with poverty. This paper gives results on accessibility to and consumption of indigenous vegetables and fruits by rural households obtained from a crosssectional surveys carried out in Matungu division, western Kenya. Accessibility was measured by; availability at local markets, own production and obtaining from natural habitats while consumption was measured using a food frequency questionnaire. Two local markets were purposively selected and 120 households drawn from the population. Data was collected using market surveys and questionnaires and summarized using tables and charts. Of the 372 market stalls only $23.5 \%$ and $13.8 \%$ of them had indigenous vegetables (9 varieties) and fruits (4 varieties) respectively. Indigenous vegetables were only cultivated by $11.8 \%$ of the households; these included only six varieties and cowpea leaves (Vigna unguilata) were the most popular. Five indigenous fruit varieties were being gathered, and guavas were the most popular. Consumption of up to 9 varieties of indigenous vegetables was observed, with cow peas, jute mallow and amaranths reporting more than $50 \%$ consumption. Six varieties of indigenous fruits had been consumed. The low accessibility to and consumption of indigenous vegetables and fruits observed posses a major nutrition problem likely to lead to poor dietary diversity and micronutrient deficiencies. Caregivers, mothers and small-holder farmers should be educated on the role of indigenous vegetables and fruits in food security, nutrition and health. They should also be encouraged and supported to sustainably grow and utilize these fruits and vegetables.
\end{abstract}

Key words: Consumption, Indigenous, Vegetables, Fruits, Micronutrients 


\section{INTRODUCTION}

Humans are dependent on consuming enough diverse foods to provide all the required nutrients to sustain life. If food systems do not provide enough diversity of foods to meet these needs continuously, malnutrition (macro and micronutrient malnutrition) will be prevalent among populations especially the resource-poor, rural communities who derive most of their income from subsistence farming [1]. Unacceptably high rates of micronutrient malnutrition persist today in spite of commitments made at the International Conference on Nutrition (ICN) in 1992 and the World Food Summit in 1996 to drastically reduce such suffering. Iron deficiency, the world's most widespread nutritional disorder, affects about 2.0 billion people, mostly women and children in developing countries. Vitamin A deficiency (VAD) affects more than 200 million people and is the major cause of preventable visual impairment and blindness. It is estimated that 250,000 children are becoming blind every year due to VAD and about half of them dying [2]. These deficiencies mostly affect resource-poor, rural households who depend on subsistence farming for food and income.

Research has shown that consumption of vegetables and fruits are the most sustainable way of reducing and controlling micronutrient deficiencies in resourcepoor communities. Indigenous vegetables and fruits besides being micronutrient-rich have the added advantage of possessing other desirable traits. These vegetables and fruits are often easier to grow, resistant to pests and diseases and are quite acceptable to local tastes. However, in many countries, indigenous vegetables and fruits are at risk of extinction as they are being replaced by high yielding commercial varieties. When an indigenous variety is lost, it can never be recovered; there is an urgent need for intervention to avoid such a situation [3].

This paper gives results on accessibility to and consumption of indigenous vegetables and fruits among rural households in Matungu division, Western Kenya, this is a section of a comprehensive cross-sectional surveys carried out with the objective of establishing the influence of perceptions and marketing practices on consumption of traditional/indigenous foods by rural households in western Kenya.

\section{METHODOLOGY}

Matungu division is within Mumias District in Western Kenya. The division has 2 locations and 13 sub-locations and is predominantly Bantu. Two major local markets namely Ogalo and Koyonzo were purposively selected from each of the locations. Through multi-stage sampling 5 sub-locations were arrived at and 3 villages randomly selected from each sub-location constitution a total 15 villages. Household listing was done in each village and using systematic random sampling whereby from the list every $5^{\text {th }}$ household was sampled out until a total of 120 households was reached at.

Indigenous vegetables and fruits were defined as vegetables and fruits that are native to a particular region, country or area. Data collection strategies included market surveys, observation and household interview schedules and the data tools were; observation checklists and structured questionnaires. Respondents for the household

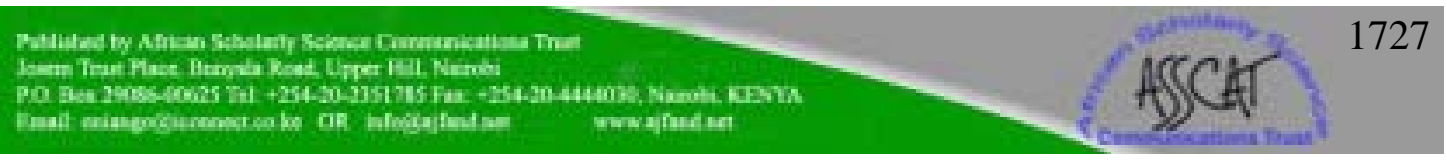


interviews were either caregivers of the homes i.e. mothers or household heads or both. Accessibility to the indigenous vegetables and fruits was measured in three ways; first, through accessing the indigenous fruits and vegetables from major local markets, since market stalls are always arranged in rows; this enables the enumerators to visit each of the stalls to make and record observations. Secondly accessing through own production and lastly through obtaining the fruits and vegetables from natural habitats through gathering from bushes and forest areas. Consumption of indigenous fruits and vegetables was assessed by use of a food frequency questionnaire with a reference period of 7 days. The food frequency questionnaire had a list of all the fruits and vegetables that are native to Matungu division. This list was derived from the Socio-cultural Profiles of Busia District, Western Kenya [4]. Data were summarized and presented using tables and graphs. The two markets purposively selected were Ogalo market with 201 stalls and Koyonzo market with 172 stalls.

\section{RESULTS}

\section{Availability of indigenous fruits and vegetables at the local markets}

Although a total of 9 different varieties of indigenous vegetables were on display at the local markets for sale, they were in only $25.6 \%$ of the stalls. Figure 1 below shows that the most popular indigenous vegetable was cowpea leaves (Vigna unguiculata) where more than $23 \%$ of the stalls had it displayed for sale; this was followed by Jute mallow (Corchorus olitorius) (11.7\%).

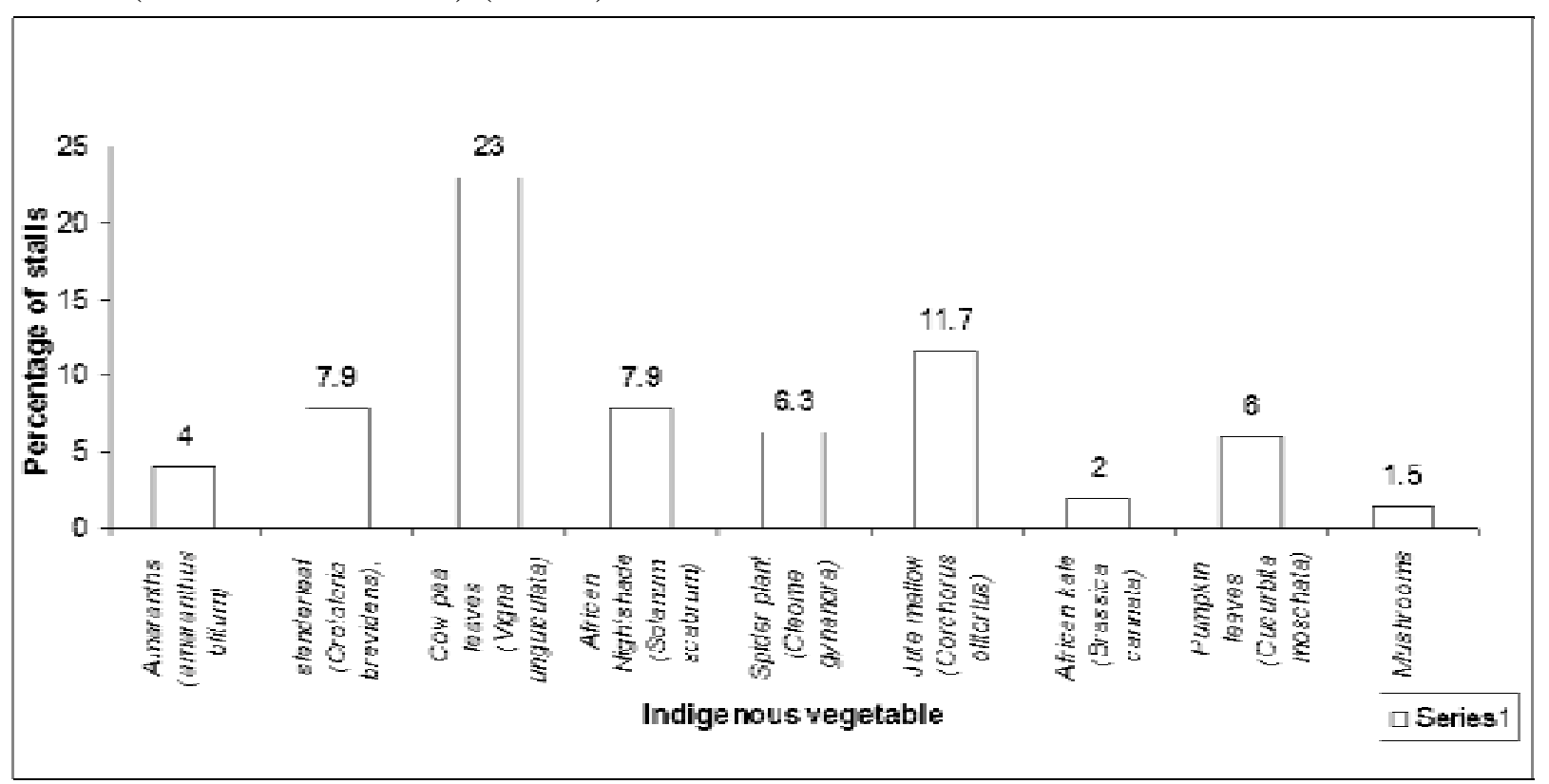

Figure 1: Availability of indigenous vegetables at the two Local Markets (Ogalo and Koyonzo) $\mathrm{N}=372$

Informal interviews with the vendors suggested that availability of a particular kind of vegetable at local markets implied that its demand was high. The number of stalls with slender leaf and African night shade were equal while mushrooms and African

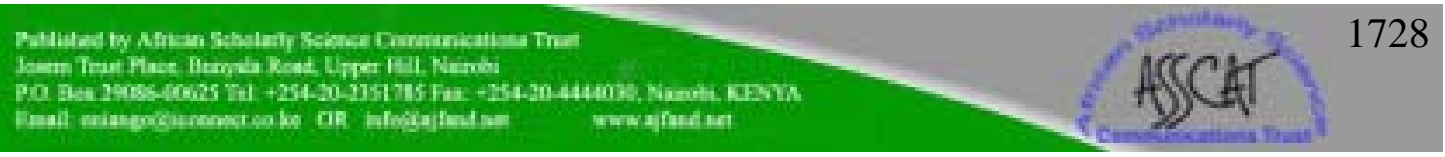


kale were in the least number of stalls. Although mushrooms are from the fungi group they were classified as vegetables because of the way they are used within this particular community,

Only 6 stalls (1.5\%) and 7 stalls (2\%) had mushrooms and African kale, respectively, displayed for sale (see Fig. 1).

Although the variety of fruits at the local markets was high (10 varieties), only four could be classified as indigenous (Fig.2). These included lemons, guavas, tamarind and jack fruit. The stalls with indigenous fruits were less than $14 \%$ with lemons being the most popular followed by guavas. The least popular indigenous fruit was the jackfruit because of its use within this particular community, with only $2.5 \%$ of the stalls having it (Fig. 2).

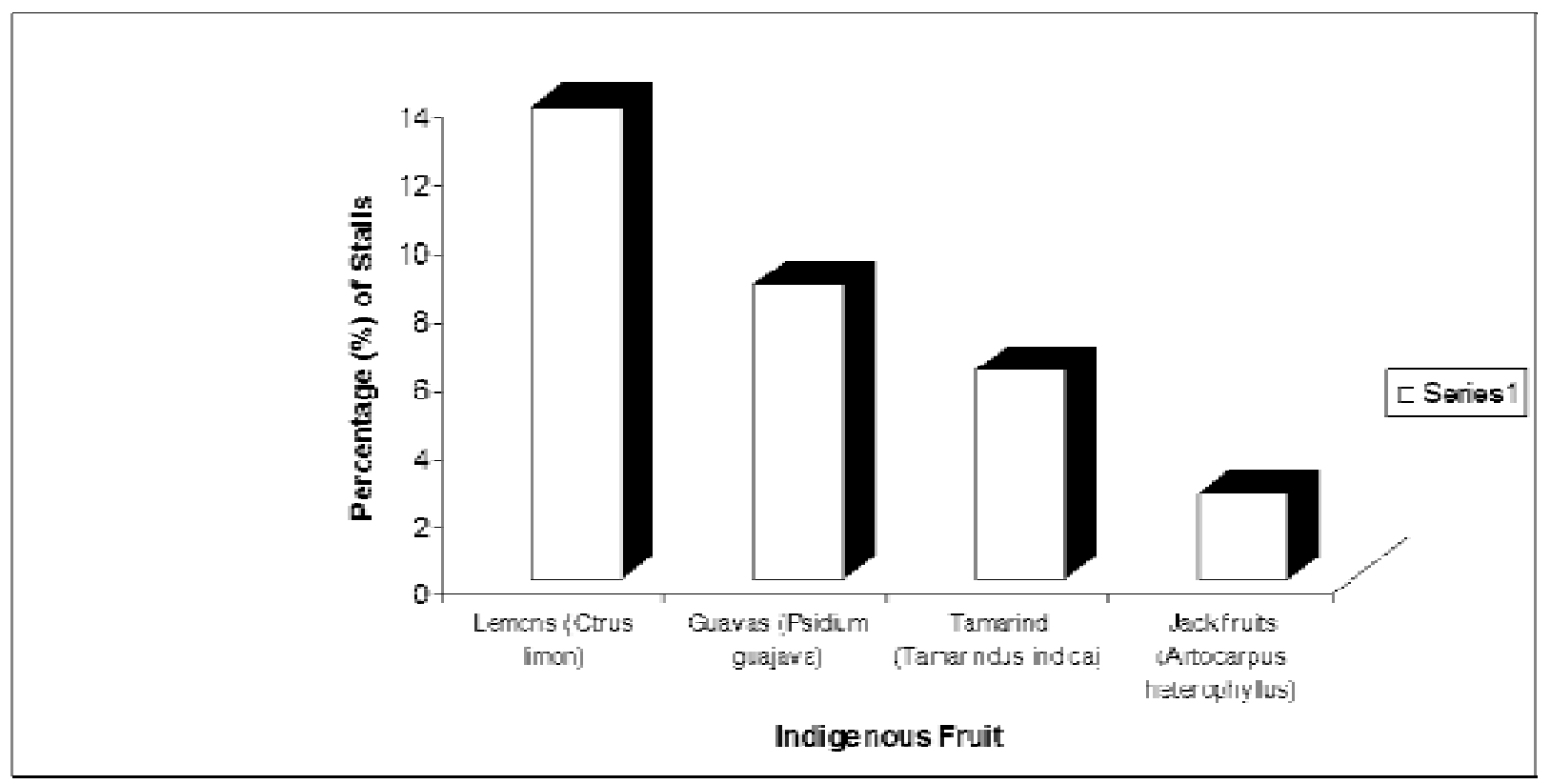

Figure 2: Availability of indigenous fruits at the two Local Markets (Ogalo and Koyonzo) $\mathbf{N}=372$

\section{Accessibility to indigenous fruits and vegetables through own production and gathering}

The findings of this study indicated that only 6 varieties of indigenous vegetables were being grown by the 120 households with only $15.8 \%$ (19) of the households growing them (Table 1). Of the $15.8 \%$ households, $93.5 \%$ of them were growing cowpea leaves. There were no indigenous fruits being grown by the households. There were guava and jackfruit trees in $50 \%$ and $3.3 \%$ of the homesteads, respectively but they were scattered in the farms and nearby forest areas and were growing naturally. 
None of the households indicated gathering of vegetables but more than $50 \%$ of the households reported having gathered indigenous fruits. Four varieties of the fruits had been gathered with guavas being the most popular (Table 2).

\section{Consumption of indigenous vegetables and fruits}

Households reported having consumed 9 different varieties of indigenous vegetables and 6 varieties of indigenous fruits. The most popular indigenous vegetable was cowpea leaves, which had been consumed by $85.0 \%$ of the households and was closely followed by jute mallow (63.3\%) (Table 3 ).

The consumption of guavas was popular at household level (26.7\%), followed by consumption of lemons with $20.8 \%$ of the households reporting consumption in the last seven days preceding the survey. The lowest consumption was in the yellow plum (Ximenia Americana) and jack fruits (Artocarpus heterophylus) (Fig. 3).

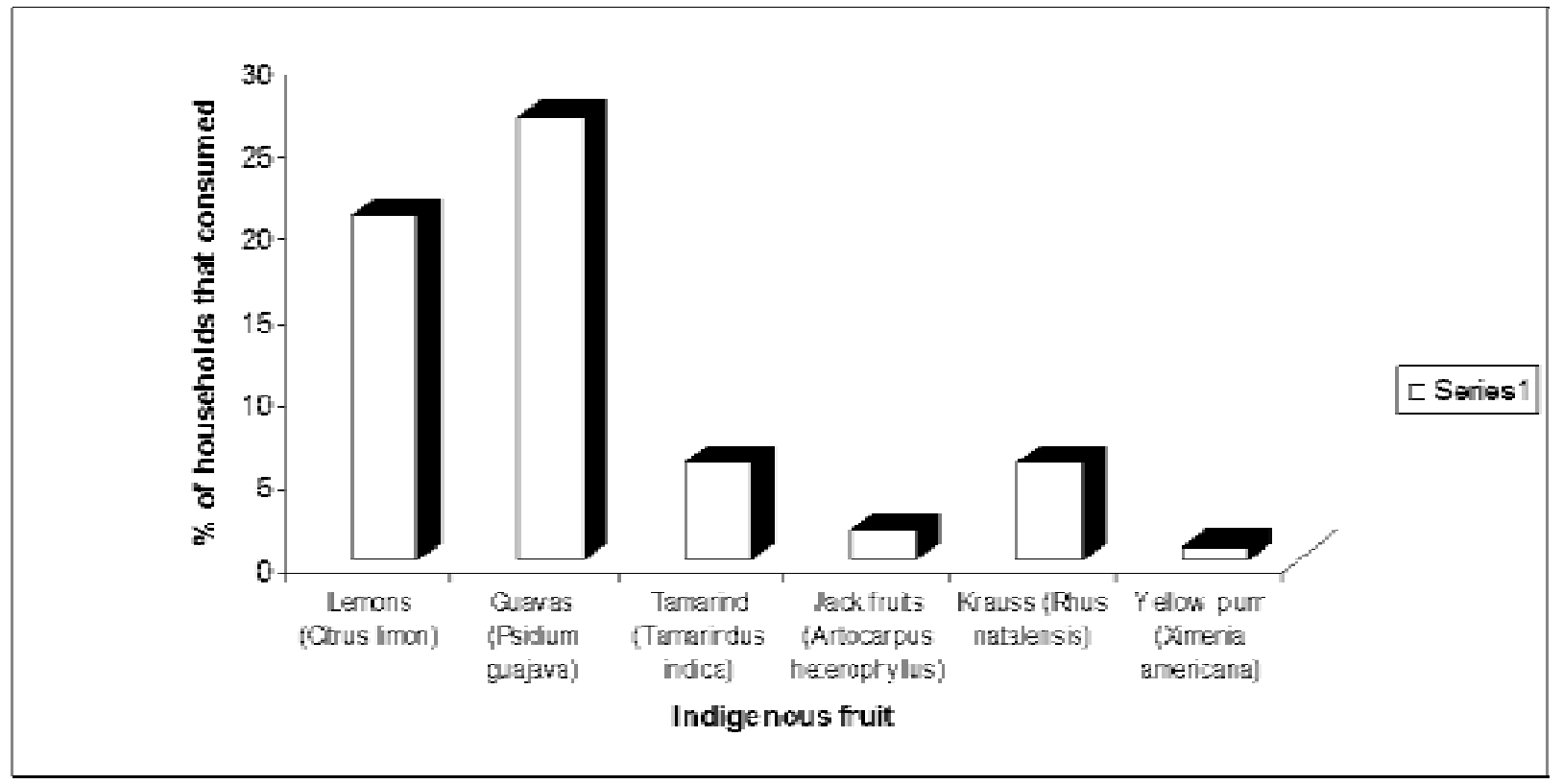

Figure 3: Consumption of indigenous fruits by rural households $\mathrm{N}=120$

\section{DISCUSSION}

Leafy and fruit vegetables form a significant part of the traditional diets of agricultural communities. About 200 indigenous plant species are used as leafy vegetables in Kenya. Only a few (4) have been fully domesticated, more (15) are semi-domesticated while the majority remains wild [5]. A survey carried out in the same province though in a different division revealed that indigenous vegetables such as leaf amaranth (Amaranthus blitum), pumpkin leaf (Cucurbita maschata), jute mallow (Corchorus olitorius), cowpea leaves (Vigna unguiculata) and mushrooms were popular and were either gathered from bushes or grown by households [6]. Wild fruits were gathered 
and mainly eaten on the spot by anybody. These diverse sources of food provided essential nutrients to the people and also acted as safety nets before harvest [4].

\section{Accessibility to indigenous fruits and vegetables}

Kenya has many wild and weedy species of edible leafy vegetables and fruits. While a few of these species have been domesticated or are semi-domesticated, most grow as weeds or wild in virgin or in disturbed and/or cultivated areas [7]. Despite this the findings of this study showed low accessibility to indigenous fruits and vegetables. These results are similar to those observed during a market survey carried out in western Kenya to assess production, marketing and utilization of traditional vegetables [8]. At household farm production 6 varieties of indigenous vegetables were being grown while no indigenous fruits were cultivated by any of the 120 households surveyed. Among the 9 and 4 types of indigenous vegetables that could be accessed from the local markets and at household farm level, respectively cow pea leaves were the most popular (Fig. $1 \&$ Table 2). According to the community this is because cowpea can withstand harsh conditions and its yield is always higher than that of the other indigenous vegetables; in addition both its leaves and seeds are used as food. The popularity of cowpeas was also observed in a study done in the eastern slopes of Mount Kenya, where more than $50 \%$ grew the vegetable crop and it was used both as vegetable and grain [9]. Although other indigenous vegetables like African nightshades (Solanum scabrum), spider plant (Cleome gynandra), African kale (Brassica carinata) and mushrooms were used as food and were popular among the Luhya community [4, 6], their availability at the local markets was low. Other indigenous vegetables that were more accessible included slender leaf (Crotalaria brevidens), Jute mallow (Corchorus olitorius) and pumpkin leaves (Cucurbita moschata) while the African kale and the mushrooms were in less than/equal $2 \%$ of the stalls (Fig. 1 and Table 1). The popularity of slender leaf and Jute mallow could be attributed to the fact that it is common among the community in western Kenya to cook two or three indigenous vegetables together and the most common mixture is that of cowpea leaves, jute mallow and slender leaf [4].

Some older documents have reported that to supplement the supply of cultivated vegetables, women in western Kenya gathered wild greens especially during the dry season [10].

Some vegetables were gathered irrespective of the season due to their delicacy and popularity including 'enderema' (Basella alba) [10].

The results of this study were different indicating great change in practices of people most likely due to depletion of natural habitats of their vegetables or the attribution of these activities to poverty.

The low number of indigenous fruits at the local markets could be due to the fact that current agricultural systems tend to be restricted to a narrow range of exotic fruits (for example mango, avocado, citrus and so on) [11]. The most popular fruit varieties were lemons followed by guavas. The popularity of the lemons could be due to their use as

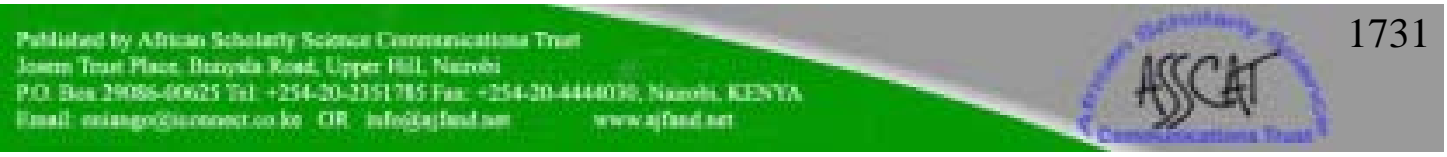


enrichment in porridge; most households are not able to afford sugar so using lemons and tamarinds in adding flavor to porridge is a common practice among households in western Kenya. This is a good practice that should be enhanced since citrus fruits are well known for their high value in vitamin $\mathrm{C}$ as compared to sugar which is just empty calories [3].

Although none of the households reported growing indigenous fruits, the guavas, tamarind, and jackfruit were still being gathered because some community members still have the fruit trees scattered in their farms and nearby forest areas [9]. This also explains the presence of these indigenous fruits at the local markets. The decrease in the presence of indigenous fruit trees within the community poses a great problem to the nutrition and even health of the community members; some of these trees and fruits were not only useful as a fruit but they also had medicinal values. Having a wide range of indigenous fruit trees available in many areas can enable farmers to meet their varied household needs for food, nutrition and medicines. These species are often part of the traditional diet and culture and the subject of a body of indigenous knowledge regarding their management and use [11].

The level of gathering was generally low, confirming that gathering of indigenous vegetables and fruit is still associated with poverty and primitive practice $[12,13]$. The low level of accessibility to indigenous fruits and vegetables could also be explained by the increasing pressure on both wild habitats and agricultural land. Due to demographic and socioeconomic changes, the ecological niches of many indigenous fruits and leafy vegetables are fast disappearing, and genetic erosion is therefore rapid [7]. At the same time, the cultural status of these valuable food plants has declined as official policy has given priority to growing crops that suit urban tastes and that are higher yielding. An example of this is the introduction of exotic vegetables, which despite their inferior nutrient content have become more prestigious than local vegetables, slowly causing the latter to disappear. Furthermore, modern agricultural approaches in Kenya, as in much of Africa, often discourage farmers from growing their indigenous crops and cultivars. As a result, the genetic resource base of food security is gradually being undermined [7].

\section{Consumption of indigenous vegetables and fruits}

Consumption of vegetables in sub-Saharan African countries is low as compared to other countries like those in Asia, and Latin America. World Health Organization (WHO) and Food and Agricultural Organization (FAO) recommend that a person should consume 400 grams of vegetable daily, or $146 \mathrm{~kg}$ per year [14]. Indigenous fruits and vegetables have been verified to be superior nutritionally compared to exotic fruits and vegetables. They are good sources of vitamins, minerals and fibre. Consumption of indigenous vegetables observed in this study is considered low. Kenya (Luo region) confirmed a list of 72 vegetable varieties that have both nutritional and medicinal value of which 29 were taxonomically confirmed. In another study within the same 'Luhya' tribe, more than 10 varieties of indigenous vegetables were made into stew to go with 'ugali' (local staple made from maize meal) [15]. Just as observed in the markets and household farm production, cowpea leaves and jute mallow were still the most popular indigenous vegetables among the 9 varieties that

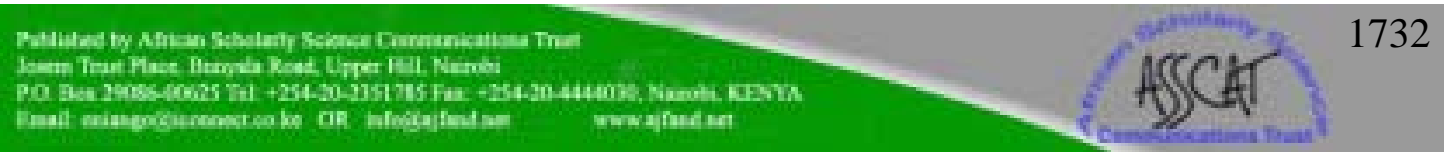


had been consumed by the 120 households surveyed. The two vegetables had been consumed by more than $60 \%$ of the households. The other popular vegetable variety was amaranths, despite the fact that availability at local markets and at household farms was low. About 50.8\% of the households reported having consumed it in the last 7 days preceding the survey (Table 3). The popularity of cowpeas and amaranth was also observed in a study carried out in eastern Kenya where more than half of the farmers were growing and consuming them [7]. The popularity of Jute mallow can be explained by the fact that, it is always cooked together with the cowpeas leaves.

A wide range of indigenous fruit trees available in many areas can enable rural households to meet their varied household needs for food, nutrition and medicines. These species are often part of the traditional diet and culture and the subject of a body of indigenous knowledge regarding their management and use [11], Despite this their consumption levels have been decreasing with time as more emphasis is directed towards the exotic fruit varieties. The findings of this study showed that the fruits at the markets were similar to those that had been consumed at household level apart from Rhus natalensis ('krauss') and Ximenia americana (yellow plum). This, therefore, indicated that most households acquire their indigenous fruits from the local markets and they gather a few varieties from bushes and scattered trees within their farms.

\section{CONCLUSION}

Although indigenous fruits and vegetables are culturally known and acceptable to local tastes, rural households in western Kenya access few of them and are, therefore, not able to make maximum use of them. This is because their availability at the local markets is low and majority of the community members are not growing these indigenous food items in their farms. In addition, the practice of gathering food items from bushes and forest areas has gone down in western Kenya.

Although the accessibility to indigenous fruits and vegetables is low, more varieties of vegetables can be accessed as compared to fruits at both market and household levels. The accessibility to indigenous fruits and vegetables through local markets, production at household farms and gathering from bushes and forests greatly influences their consumption at household level.

\section{RECOMMENDATIONS}

It has been recognized that an important factor in improving the viability of rural livelihoods in developing countries is the promotion of sustainable agriculture. As opposed to relying solely on cash crops, this can be more easily achieved through the promotion of the nutritious indigenous vegetables and domestication of various indigenous fruit trees that can be cultivated and owned by smallholder farmers. These vegetables and fruits can grow under a wide range of environmental conditions, and several species are more resistant to pests and diseases and are more nutritious and could most sustainably reduce micronutrient deficiencies in resource-poor 
communities [2]. Therefore, through multi-functional and integrated farming systems, these indigenous plants can support environmental and social sustainability by providing food as well as promoting economic growth [16]. It is, therefore, important to promote their production and consumption. This can be done through sensitizing a community's own resource persons on the nutrition and adaptability of these products. The indigenous vegetables and fruits could also be incorporated in the on-going foodbased approaches of diversifying home and kitchen gardens. This could be further sustained by the agricultural sector in collaboration with non-Governmental Organizations working together to ensure these plant species do not disappear and that community members have continued access to seeds and other planting materials.

\section{ACKNOWLEDGEMENT}

The authors acknowledge Nutrition Third World (NTW) based in Belgium, for funding the research project from which the results of this paper are derived. The administration officers and the community members involved in the survey are also acknowledged. Last but not least, the authors thank Bioversity International for the staff time spent during the writing of this paper. 
Table 1: Indigenous vegetables grown by the households $\mathrm{N}=19$

\begin{tabular}{|l|l|}
\hline Type of Indigenous vegetable & \% of household growing \\
\hline Amaranths (Amaranthus blitum) & 5.9 \\
\hline Cow pea leaves (Vigna unguiculata) & 93.5 \\
\hline slenderleaf (Crotalaria brevidens) & 29.4 \\
\hline African Nightshade (Solanum scabrum) & 7.3 \\
\hline Jute mallow (Corchorus olitorius) & 11.7 \\
\hline Pumpkin leaves (Cucurbita moschata) & 11.7 \\
\hline
\end{tabular}

Table 2: Indigenous fruits gathered by the households $N=120$

\begin{tabular}{|l|l|}
\hline Type of Indigenous Fruit & \% of households gathering \\
\hline Guavas (Psidium guajava) & 87.5 \\
\hline Krauss (Rhus natalensis) 'usangula' & 2.1 \\
\hline Tamarind (Tamarindus indica) & 0.8 \\
\hline Jack fruit (Artocarpus heterophyllus) 'tsinduri’ & 0.8 \\
\hline
\end{tabular}


Table 3: Consumption of Indigenous vegetables among the households N=120

\begin{tabular}{|l|l|}
\hline Type of Indigenous vegetable & \% of households having consumed \\
\hline Amaranths (amaranthus blitum) & 50.8 \\
\hline Slenderleaf (Crotalaria brevidens), & 35 \\
\hline Cowpea leaves (Vigna unguiculata) & 85.8 \\
\hline African Nightshade (Solanum scabrum) & 25.8 \\
\hline Spider plant (Cleome gynandra) & 19.2 \\
\hline Jute mallow (Corchorus olitorius) & 63.3 \\
\hline African kale (Brassica carinata) & 4.2 \\
\hline Pumpkin leaves (Cucurbita moschata) & 32.5 \\
\hline Mushrooms & 3 \\
\hline
\end{tabular}




\section{RERERENCES}

1. Welch RM The Impact of Mineral Nutrients in Food Crops on Global Health. USDA, ARS, U.S. Plant, Soil and Nutrition Laboratory, Cornell University, Tower Road, Ithaca, NY 14853, USA.2002.

2. Aphane J, Chadha ML and MO Oluoch FAO-AVRDC International Workshop proceedings, Arusha, Tanzania, 5-8 March 2002. Increasing the Consumption of Micronutrient-rich Foods through Production and Promotion of Indigenous Foods.

3. Kader AA, Penelope PV and EL Gene Nutritional Quality of fruits, Nuts and Vegetables and their Importance in Human Nutrition. Department of Pomology, University of California, Kika de la Garza Subtropical Agricultural Research Centre, USDA/ARS. 2006.

4. Were GS and R Soper Food Resources for the Luhya. Kenya Social-Cultural Profiles: Busia District. Institute of African Studies, University of Nairobi. Chap 6 \& 7. 1989.

5. Maundu PM The status of Traditional vegetable utilization in Kenya. National Museum of Kenya, Nairobi, Kenya. Proceedings of the IPGRI International workshop on Genetic Resources of Traditional Vegetables in Africa. Conservation and use 29-31 ${ }^{\text {st }}$ August 1995, ICRAF- HQ Nairobi, Kenya.

6. Abukutsa-Onyango MO Unexploited potential of indigenous African vegetables in Western Kenya. Maseno Journal of Education, Arts and Science (MJEAS) Vol. 4 No. 2, Maseno University. Pp 105-120.2003.

7. Kemei JK, Waataru RK and EN Sememe The role of National Genebank of Kenya in the collecting, characterization and conservation of traditional vegetables. National GeneBank of Kenya, Kikuyu, Kenya. Proceedings of the IPGRI International workshop on Genetic Resources of Traditional Vegetables in Africa. Conservation and use 29-31 ${ }^{\text {st }}$ August 1995, ICRAF- HQ Nairobi, Kenya. 1995

8. Nekesa P and B Meso Traditional African Vegetables in Kenya; Production, Marketing and Utilization. Proceedings of the IPGRI International Workshop on Genetic Resources of Traditional Vegetables in Africa. Conservation and use 29-31 ${ }^{\text {st }}$ August 1995, ICRAF- HQ Nairobi, Kenya.1995

9. Kabuye SC and WG Ngugi Nutritional and Medicinal Importance of Indigenous food Plants. The Potential of Indigenous Foods. Workshop proceedings, 22-26 January, 2001. USAID. 2001.

10. Karen RW The sociological and Economic Value of Kenya's Wetlands. Proceedings of a seminar on wetlands of Kenya. 1992

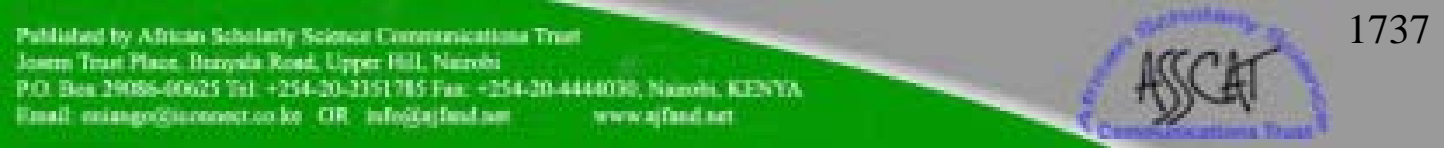


11. Schreckenberg $K$, Awono A, Degrande A, Mbosso $C$, Ndoye $O$ and $Z$ Tchoundjeu Domesticating Indigenous Fruit Trees as a Contribution to Poverty Reduction. Forest trees and livelihood, 2006, Vol 16 Pp 35-51. 1472-8028. 2006

12. John T Plant Biodiversity and Malnutrition: Simple Solutions to Complex Problems. African Journal of Food Agriculture, Nutrition and Development, on line version ISSN $1684-5378$. 2003. Retrieved on $14^{\text {th }}$ January 2004 from http://www.ajfand.net/

13. Gari AJ Traditional, neglected and underutilized crops. Plant Diversity, Sustainable Rural Livelihoods and the HIV/AIDS Crisis. UNDP \& FAO. Pp 57.2004.

14. Ruel MT Is diversity an indicator of food security or dietary quality? A review of measurement issues and research needs. FCND Discussion paper No. 140 (2002), International Food Policy Research Institute, Washington, DC, USA. 2002.

15. Mathenge $\mathbf{L}$ Nutrition value and utilization of indigenous vegetables in Kenya. KENGO, Nairobi, Kenya. Proceedings of the IPGRI International workshop on Genetic Resources of Traditional Vegetables in Africa. Conservation and use 29-31 ${ }^{\text {st }}$ August 1995, ICRAF- HQ Nairobi, Kenya. 1995.

16. Akinnefesi FK, Ajayi OC, Tchoundieu Z, Matacala P and FR Kwesiga

Indigenous Fruit Trees in the Tropics Domestication, Utilization and Commercialization. Downloaded on $1^{\text {st }}$ June 2009 from http://www.cabi.org/ 